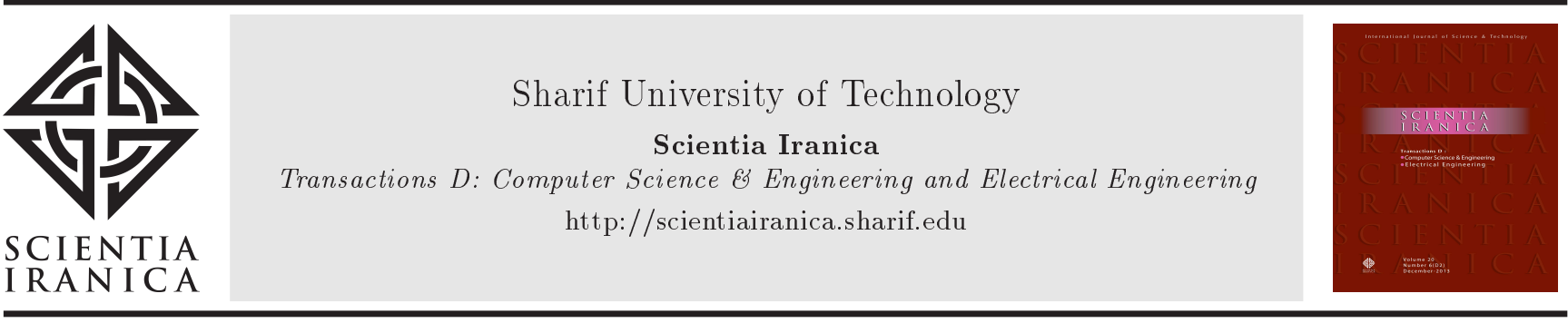

Research Note

\title{
Optimal design and analysis of a novel reluctance axial flux magnetic gear
}

\author{
S.A. Afsari* \\ Faculty of Electrical and Computer Engineering, University of Kashan, Kashan, P. O. Box 87317-53153, Iran.
}

Received 23 July 2019; received in revised form 29 November 2019; accepted 14 April 2020

\section{KEYWORDS}

Reluctance magnetic gear;

3-D FEM;

Axial flux;

Torque density;

Flux density.

\begin{abstract}
This paper proposes modeling and optimization of a new Reluctance Axial Flux Magnetic Gear (RAMG) that enjoys a stationary outer rotor and lower permanent magnet usage. Due to the insignificant use of the PMs, this structure has a higher economic interest, greater reliability, and more simple and robust structure than its conventional ones. Gear ratio and operating principles are extracted and verified using 3D Finite Element Method (FEM) simulations. Finally, parametric optimization is done based on effective dimensions in design procedure with maximum torque density objective function. The magnetic flux distributions of optimized RAMG are calculated using 3D FEM and static and dynamic magnetic torques are derived correspondingly.
\end{abstract}

(C) 2022 Sharif University of Technology. All rights reserved.

\section{Introduction}

In low-speed industrial applications, an electrical machine with a mechanical gearbox is employed to save the total volume of the system by extracting the desired torque based on the performance of the mechanical gear. The most common types of mechanical gears are spur gear, worm gear, rack pinion gear, bevel gear, and planetary gear. The torque density and the gear ratio are used to evaluate the performance of mechanical gears. In addition to the advantages of mechanical gearbox, some problems such as the need for lubrication, no overload protection, fracture and corrosion, noise, vibration, and mechanical losses have stirred up new tendencies for developing new systems called Magnetic Gears (MGs). Many initial MG technologies are inspired by mechanical counterparts. Armstrong [1] and Faus [2] introduced MGs according to a mechanical spur gear. Tsurumoto and Kikuchi

\footnotetext{
*. Tel.: +983155913480

E-mail address: afsari@kashanu.ac.ir
}

presented worm-based [3] and spiral-based MG topologies [4]. The problem with these initial MG designs is that only one to some magnets transfer torque at any given moment, hence lower torque transfer. Today's advanced MGs in their general form benefit from two rotors of high-energy Permanent Magnets $(\mathrm{PMs})$ and a middle ferromagnetic pole piece rotor called modulators [5,6]. Magnetic flux was produced by PMs modulated using ferromagnetic pole pieces to establish an effective harmonic component with different rotational speeds to rotate the opposite rotor as a gear $[4,7,8]$. This topology offers some advantages such as no contact, no wear and corrosion, no noise, no need for lubrication, and inherent overload protection $[9,10]$. The structure of novel MGs can compete with those of traditional mechanical types. Over the last decade, various structures have been introduced to increase torque density $[11,12]$, minimize cogging torque $[13,14]$, and reduce total cost $[15,16]$.

In [17], a general review of magnetic gears was presented along with a discussion of the most common and upcoming topologies and a description of the working principle. A comparison of different topologies was made in terms of gear ratio and torque density. 
In [18], a time-saving methodology was presented for designing and sizing radial MG sets. A novel hightemperature superconducting bulk coaxial MG with an eccentric pole of inner rotor and Halbach arrays of outer rotor was proposed in [19] to improve the high torque density of the MG. In [20], a novel design of rotor topology was achieved for a superconductive radial flux magnetic gear to obtain sinusoidal air-gap flux density and lower cogging torque. The method functioned based on optimization of buried magnet's pole shape in a radial flux structure, modified by using pulse width modulation technique and variable air gap length applying the supershape formula on the iron core of the inner rotor. Zhan et al. [21] investigated torque performances of magnetic gear with different configurations of the modulating ring that were characterized by the shape of modulator, the position of the interconnecting bridge, and the ratio of pole arc to pole pitch. The torque density characteristics for an axial flux magnetic gear using a fluxfocusing topology were experimentally studied in [22]. A geometric parameter sweep analysis was employed in order to maximize both the calculated volumetric and mass torque density. Many commercially available mechanical gears could operate with torque densities above $250 \mathrm{Nm} / \mathrm{L}$, while for $\mathrm{MG}$, the torque density was lower than $200 \mathrm{Nm} / \mathrm{L}$ [23]. It is implied that further improvement in the $\mathrm{MG}$ technology is still required.

Among different structures of radial flux (coaxial) [24], linear [25], transverse flux [26], arcuate [27], and axial flux, the axial flux (AFMG) structure has been widely considered [28-30]. This is because of the separation between the input and output shafts, providing the possibility of oscillation of the axes relative to each other and lower occupation of the axial space.

The magnets used in AFMGs appear in the form of a mounted or interior surface $[31,32]$. They are exposed to the impact of centrifugal force and scratch in a high-speed rotor. In addition, the high-cost ratio of PMs in the total cost of MGs is one of the fundamental challenges of conventional MGs $[15,16]$. In this paper, a novel Reluctance Axial Flux Magnetic Gear (AFMG) (RAMG) structure is introduced (based on the concepts of reluctance machines) by removing PMs in the high-speed rotor. This removal in highspeed rotors reduces the core loss and yields higher efficiency. The other PM rotors are kept stationary and the gear ratio is obtained through the high-speed reluctance rotor and the middle low-speed modulator rotor. Figure 1 shows the exploded conceptual structures of conventional $\mathrm{MG}$ and RAMG. In [33], a radial flux reluctance $\mathrm{MG}$ was introduced and compared with the traditional coaxial MG in terms of gear ratio and torque transmission. A similar structure of the reluctance MG was introduced in [34] using superconducting material in inner and outer rotors with a coaxial structure with a single middle PM rotor to achieve higher torque density against greater costs. Li et al. [35] presented a coaxial $\mathrm{MG}$ with a reluctance outer rotor and a stationary inner PM rotor. Parametric analysis and torque performance results were extracted using $2 \mathrm{D}$ Finite Element Method (FEM) analysis.

\section{Operation principle of RAMGs}

Sections of different rotors are shown in Figure 2. Magnetic field distribution and gear ratio of the RAMG can be extracted based on the general parameters given in Figure 2 as well as computation of Magneto Motive Force (MMF) distribution and reluctance distribution of different rotors. As shown in Figure 2, the magnetic field arises from stationary PM rotor and provides the desired MMF. Based on the PM's pole pitch, the distribution of MMF can be expressed in terms of Eq. (1):

$$
F_{s}=F_{s 1} \cos \left(n_{m} \alpha\right),
$$

where $F_{s 1}$ is the amplitude of MMF, $n_{m}$ the pole pair of the stationary rotor, and $\alpha$ the mechanical angle.

By rotating the middle modulator rotor, the reluctance of the magnetic path may vary. According to the structure of the modulator low-speed rotor, the permeance distribution can be expressed in Eq. (2):

$$
\Lambda_{m}=\lambda_{m 0}+\lambda_{m 1} \cos \left(p_{s} \alpha-p_{s} \omega_{r} t+p_{s} \alpha_{m 0}\right),
$$

where $\lambda_{m 0}$ and $\lambda_{m 1}$ are the mean and amplitude of modulator permeance, respectively. $p_{s}, \omega_{r}$, and $\alpha_{m 0}$ are the number of modulators, angular speed, and initial angle of the low-speed modulator rotor, respectively.

The high-speed rotor rotates with the reluctance changing. Similarly, the distribution of the permeance of this rotor can also be expressed in Eq. (3):

$$
\Lambda_{r}=\lambda_{r 0}+\lambda_{r 1} \cos \left(n_{r} \alpha-n_{r} \omega_{m} t+n_{r} \alpha_{r 0}\right)
$$

where $\lambda_{r 0}$ and $\lambda_{r 1}$ are the mean and amplitude of highspeed permeance, respectively. $n_{r}, \omega_{m}$, and $\alpha_{r 0}$ are the number of reluctance teeth, angular speed, and initial angle of the high-speed rotor, respectively.

Magnetic flux is produced by the magnets and it passes from the variable reluctance space of the middle rotor to the reluctance rotor, which can be expressed in Eq. (4) as shown in Box I. Based on the above-mentioned relationship, the main harmonics can be determined to create an effective gear ratio and torque transmission. The 8 th and 9 th sentences of Eq. (4) are the magnetic flux components modulated by modulators. The condition of pole pairs to obtain the gear ratio between the high-speed rotor and the 


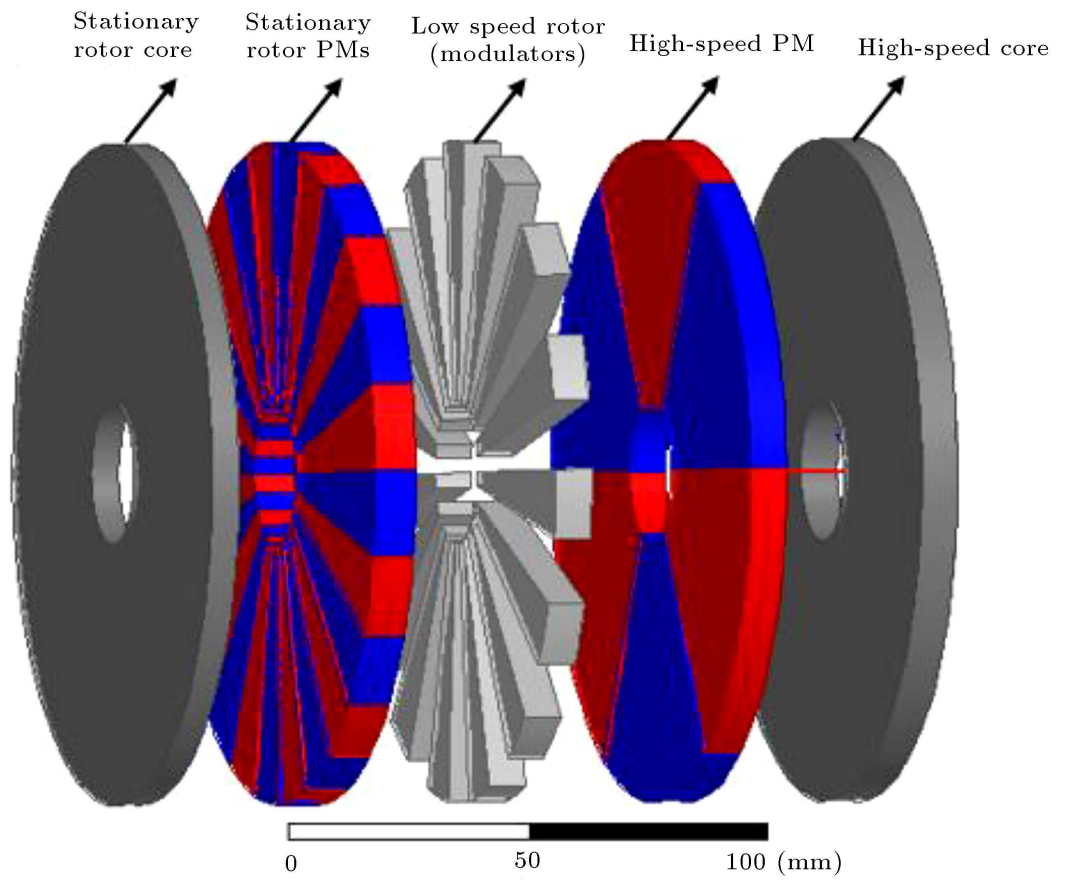

(a)

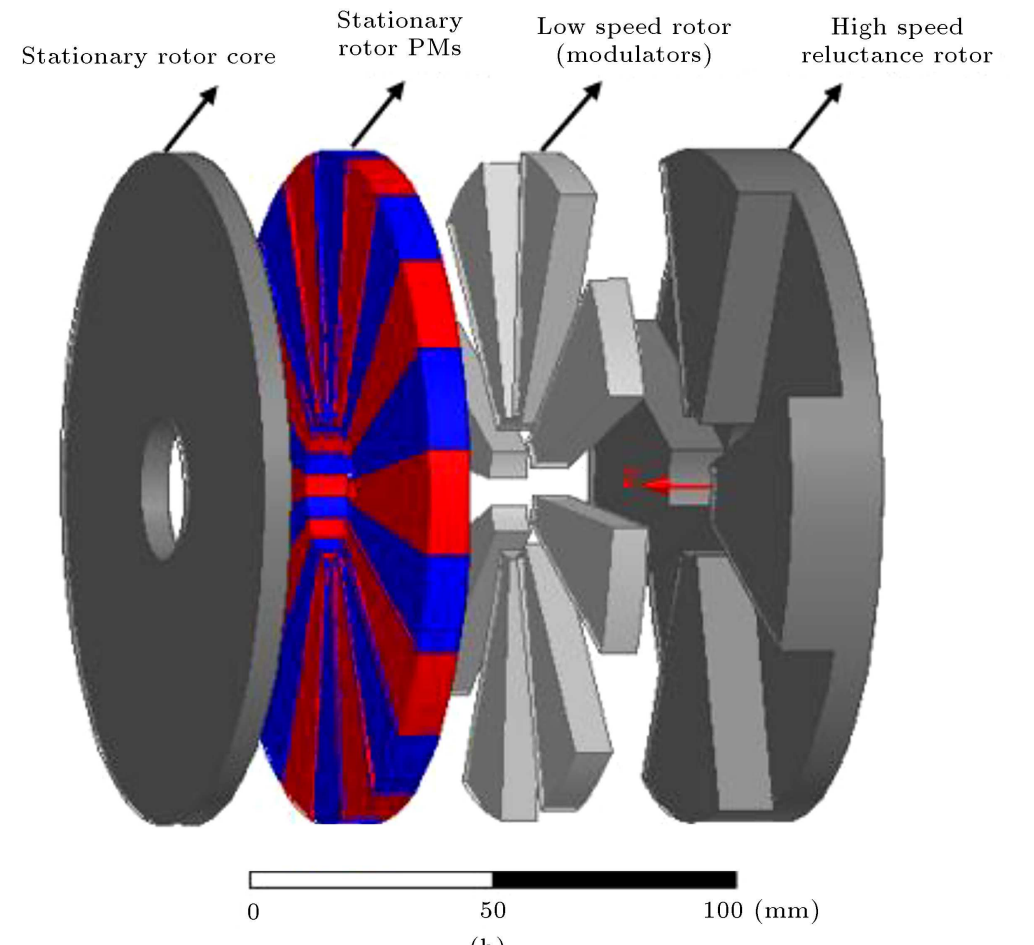

(b)

Figure 1. Exploded view of (a) conventional AMG and (b) RAMG.

low-speed rotor, which can rotate the output rotor at different speeds compared to the input rotor, holds in these sentences $\left(n_{m} \neq 0, n_{m}=p_{s} \pm n_{r} \pm n_{m}\right)$. Hence, the angular speed of magnetic flux density is equal to: $p_{s} \omega_{r} \pm n_{r} \omega_{m}$. Due to the lack of permanent magnets in the high-speed and low-speed rotors, the angular speed of magnetic flux density in the high-speed rotor and low-speed rotor is zero. Hence, the gear ratio can be calculated by Eq. (5):

$$
0=p_{s} \omega_{r} \pm n_{r} \omega_{m} \Rightarrow G_{r}=\frac{\omega_{m}}{\omega_{r}}=\mp \frac{p_{s}}{n_{r}} .
$$

Thus, it can be concluded that the relation among the number of poles, modulators, and reluctance teeth must be equal to Eq. (6):

$$
2 n_{m}=P_{s} \pm n_{r} \text {. }
$$




$$
\begin{aligned}
\phi(\alpha, t)= & F_{s} \Lambda_{m} \Lambda_{r}=F_{s 1} \lambda_{m 0} \lambda_{r 0} \cos \left(n_{m} \alpha\right)+0.5 F_{s 1} \lambda_{m 0} \lambda_{r 1}\left[\cos \left(\left(n_{r}+n_{m}\right) \alpha-n_{r} \omega_{m} t+n_{r} \alpha_{r 0}\right)\right. \\
& \left.+\cos \left(\left(n_{r}-n_{m}\right) \alpha-n_{r} \omega_{m} t+n_{r} \alpha_{r 0}\right)\right]+0.5 F_{s 1} \lambda_{m 1} \lambda_{r 0}\left[\cos \left(\left(p_{s}+n_{m}\right) \alpha-p_{s} \omega_{r} t+P_{s} \alpha_{m 0}\right)\right. \\
& \left.+\cos \left(\left(p_{s}-n_{m}\right) \alpha-p_{s} \omega_{r} t+P_{s} \alpha_{m 0}\right)\right]+0.25 F_{s 1} \lambda_{m 1} \lambda_{r 1}\left[\operatorname { c o s } \left(\left(p_{s}+n_{r}+n_{m}\right) \alpha-\left(p_{s} \omega_{r}+n_{r} \omega_{m}\right) t\right.\right. \\
& \left.+\left(p_{s} \alpha_{m 0}+n_{r} \alpha_{r 0}\right)\right)+\cos \left(\left(p_{s}-n_{r}+n_{m}\right) \alpha-\left(p_{s} \omega_{r}-n_{r} \omega_{m}\right) t+\left(p_{s} \alpha_{m 0}-n_{r} \alpha_{r 0}\right)\right) \\
& +\frac{\cos \left(\left(p_{s}+n_{r}-n_{m}\right) \alpha-\left(p_{s} \omega_{r}+n_{r} \omega_{m}\right) t+\left(p_{s} \alpha_{m 0}+n_{r} \alpha_{r 0}\right)\right)}{} \\
& +\underline{\left.\cos \left(\left(p_{s}-n_{r}-n_{m}\right) \alpha-\left(p_{s} \omega_{r}-n_{r} \omega_{m}\right) t+\left(p_{s} \alpha_{m 0}-n_{r} \alpha_{r 0}\right)\right)\right]}
\end{aligned}
$$

The positive or negative sign will be selected according to the coupled harmonic. Due to the large harmonic number and variation in magnetic flux, the transmitted torque is expected to be subject to high fluctuations.

\section{Modeling and parametric optimization of RAMG}

In order to ensure the optimal RAMG design using finite element software, different dimensions of the gear are optimized according to Figures 2 and 3 . The purpose of optimization is to maximize the torque density transmission in this structure considering the design constraints.

3D FEM simulation predicts the best results in terms of mesh balancing reliability, speed, quality, size, and design characteristics. Flux density distribution and static torque calculations are performed through steady 3D FEM simulations, while cogging torque calculations are performed using transient 3D FEM.

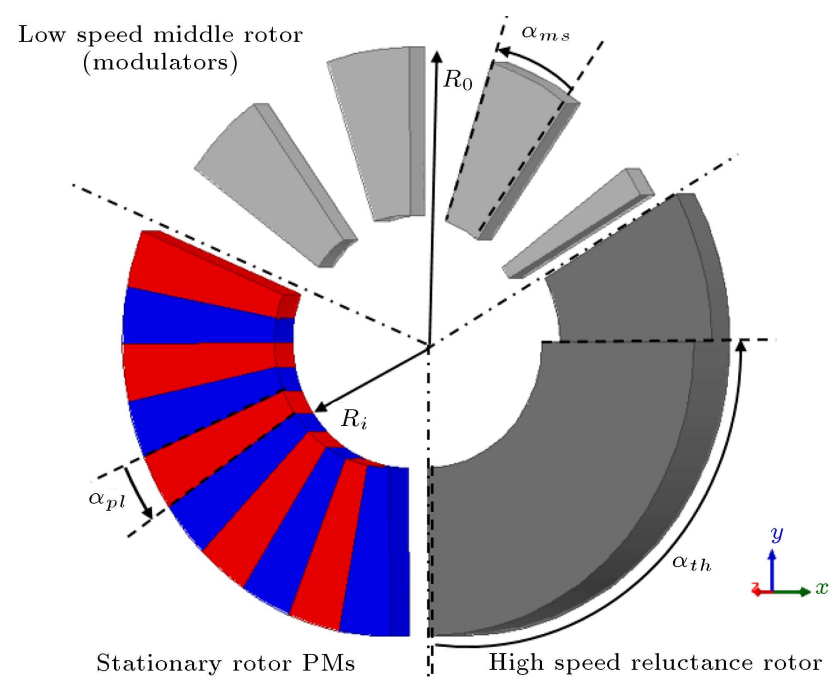

Figure 2. Geometric dimensions of RAMG.
The nonlinear discretized governing equations that model MG performance are solved at each time step using a Newton-Raphson iteration (tolerance $10^{-3}$ and relaxation factor 0.15 ) with a Multifrontal Massively Parallel Sparse Direct Solver (MUMPS) for the linear sub-system at each iteration (precision for scaling $\left.10^{-3}\right)$. To produce optimal mesh, an adaptive mesh refinement is performed in critical regions using an iterative procedure. The mesh is refined (20 times, leading to the reduction of energy error from $37.8 \%$ in the first pass to $0.0312 \%$ in the last pass) in areas of highest error density. When changes in selected parameters (percentage of energy error) are less than $0.1 \%$, the mesh refinement terminates. The optimization takes about 57 hours by using a core i7-8700 6-core processor and 64GB RAM. All simulations are done around pullout torque (maximum static torque) point.

Optimization results of different parameters are shown in Table 1 based on maximum torque density objective function. These results are derived using 3D FEM modeling and constraints considered in Table 1. In this process, the inner and outer radii, air gaps, number of poles, and gear ratio are considered constant.

According to Table 1, the gear ratio will be $+1: 5$. Increasing the thickness of the PMs increases the MMF and, on the other hand, increases the reluctance of magnetic path; therefore, the optimal thickness is obtained $9 \mathrm{~mm}$ according to Table 1 . The reluctance of teeth and modulators' thickness not only affect the total reluctance but also cause leakage flux and weak magnetic coupling. Thus, the optimum lengths of $11 \mathrm{~mm}$ and $8 \mathrm{~mm}$ are obtained for teeth and modulators, respectively. Core length depends on the saturation level of core due to the flux density of PMs. According to the results of the optimization, output performances of RAMG can be extracted. The paths of magnetic potential lines and magnetic field path in different regions of optimal RAMG are shown in Figure 4. 


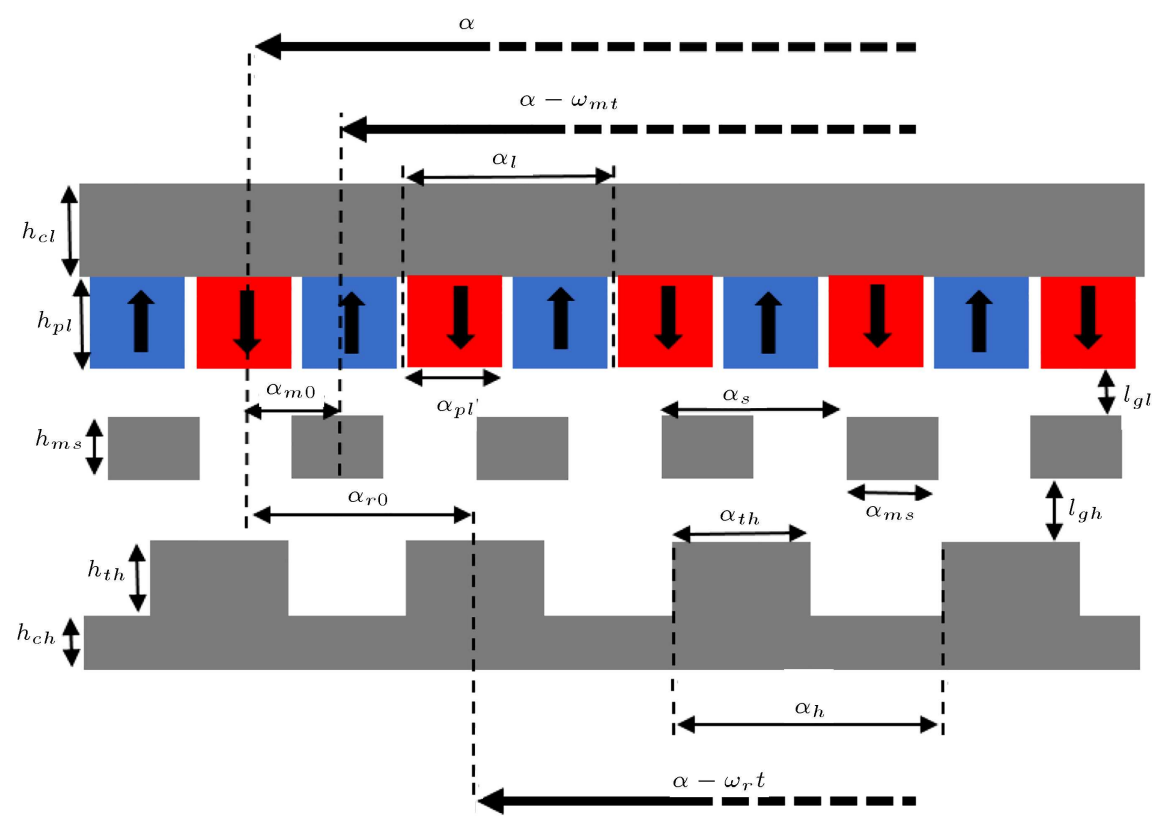

Figure 3. Optimization parameters in different layers of RAMG.

Table 1. Optimal design parameters of RAMG.

\begin{tabular}{|c|c|c|c|c|}
\hline Design parameter & Material & Variable & Initial value & Optimal value \\
\hline Number of high-speed rotor teeth & - & $n_{r}$ & 4 & 4 \\
\hline Number of stationary rotor pole pairs & - & $n_{m}$ & 8 & 8 \\
\hline Number of low-speed modulators & - & $p_{s}$ & 20 & 20 \\
\hline Air gap length & - & $l_{g l}, l_{g h}$ & $1 \mathrm{~mm}$ & $1 \mathrm{~mm}$ \\
\hline Outer radius & - & $R_{o}$ & $70 \mathrm{~mm}$ & $70 \mathrm{~mm}$ \\
\hline Inner radius & - & $R_{i}$ & $15 \mathrm{~mm}$ & $15 \mathrm{~mm}$ \\
\hline Axial length of PMs & $\mathrm{NdFeB-35}$ & $2 \mathrm{~mm} \leq h_{p l} \leq 10 \mathrm{~mm}$ & $4 \mathrm{~mm}$ & $9 \mathrm{~mm}$ \\
\hline Axial length of stationary core & NGO-M400-50A5 & $3 \mathrm{~mm} \leq h_{c l} \leq 8 \mathrm{~mm}$ & $4 \mathrm{~mm}$ & $6 \mathrm{~mm}$ \\
\hline Axial length of modulators & NGO-M400-50A5 & $2 \mathrm{~m} \leq h_{m s} \leq 10 \mathrm{~mm}$ & $5 \mathrm{~mm}$ & $8 \mathrm{~mm}$ \\
\hline Axial length of reluctance teeth & NGO-M400-50A5 & $2 \mathrm{~mm} \leq h_{t h} \leq 15 \mathrm{~mm}$ & $5 \mathrm{~mm}$ & $11 \mathrm{~mm}$ \\
\hline Axial length of high-speed core & NGO-M400-50A5 & $5 \mathrm{~mm} \leq h_{c h} \leq 10 \mathrm{~mm}$ & $5 \mathrm{~mm}$ & $8 \mathrm{~mm}$ \\
\hline Pole arc to pole pitch ratio of PMs & - & $0.25 \leq \alpha_{p l} / \alpha_{l} \leq 0.5$ & 0.4 & 0.5 \\
\hline Teeth arc to teeth pitch ratio & - & $0.25 \leq \alpha_{t h} / \alpha_{h} \leq 0.5$ & 0.3 & 0.5 \\
\hline Slot opening of modulators & - & $0.25 \leq \alpha_{m s} / \alpha_{s} \leq 0.5$ & 0.5 & 0.5 \\
\hline Remanence of PMs & - & $B_{r}$ & $1.2 T$ & $1.2 T$ \\
\hline
\end{tabular}

Figure 5 shows the axial component of magnetic field distribution in the middle height and radius of high- and low-speed air gaps. Proximity to the source of MMF in the high-speed air gap increases the amplitude of this component. As can be seen in Figure 6, the amplitude of magnetic field distribution in different regions shows some hotspots of about $2.3 T$ at sharp points at some moments.
According to the above structure and dimensions of RAMG, the static and dynamic torques in highand low-speed rotors can be calculated through 3D FEM analysis, as given in Figures 7 and 8, respectively. In static analysis, the reluctance rotor rotates about 90 mechanical degrees and two other rotors are kept stationary. Calculated static torque is equal to 1.5 Nm and 7.5 Nm for high-speed and low-speed 

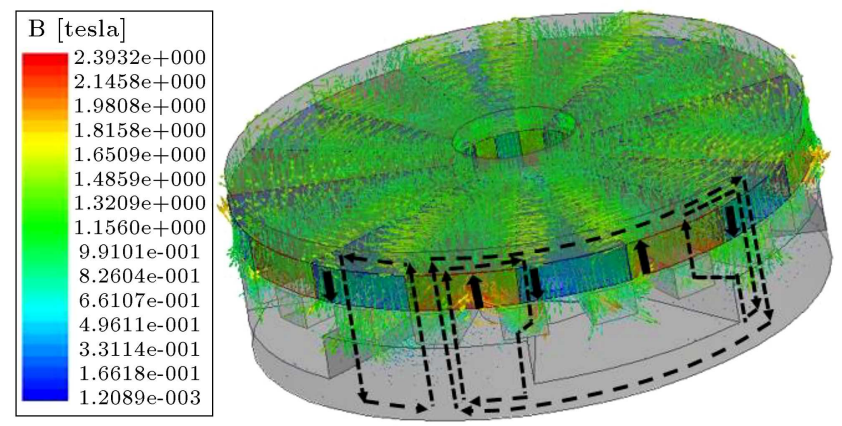

Figure 4. Flux lines path in RAMG.

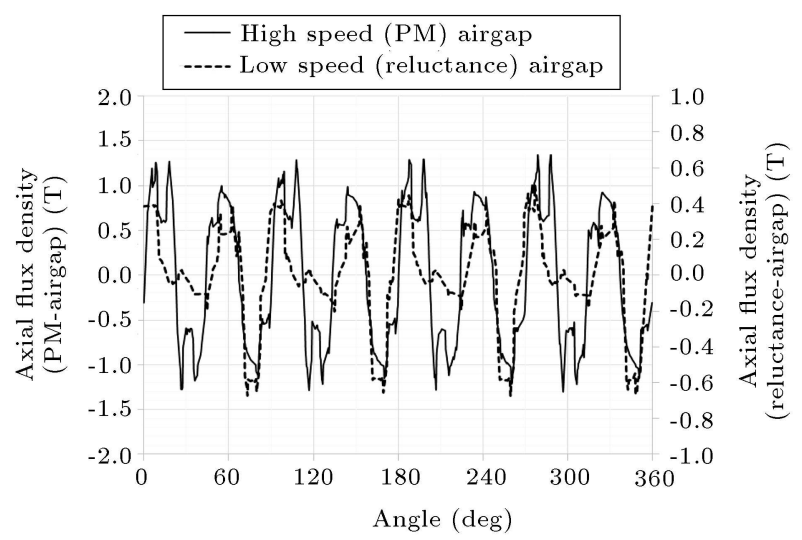

Figure 5. Axial flux density distribution in high- and low-speed air gaps of optimal RAMG.

rotors, respectively. Maximum static torque occurs at an initial zero mechanical degree. Thus, the initial mechanical angle for dynamic simulations will be set at the maximum point of static torque, called pullout torque. In dynamic simulation, the high-speed reluctance rotor and low-speed modulator rotors rotate in the same directions according to the gear ratio. Thus, the average torque of about $1.5 \mathrm{Nm}$ and $7.5 \mathrm{Nm}$ and cogging torque of about $4.3 \mathrm{Nm}$ and $1.7 \mathrm{Nm}$ for high-speed and low-speed rotors can be obtained, respectively. As can be seen, the dynamic torque has considerable pulsation and cogging torque, because the gear ratio is an integer number; therefore, all the teeth meet the edge of modulators and PMs at the same time and reluctance directly changes effects on torque transmission. Results of optimal RAMG and initial RAMG are presented in Table 2.

\section{Conclusion}

In this paper, a novel RAMG was introduced. This model exhibited superior advantages over conventional axial flux MGs, especially in reducing PM consumption and facilitating construction. The same treatment of analytical analysis and 3D FEM at the gear ratio pointed to the high precision of the proposed model. The 3D FEM was employed to investigate the effects

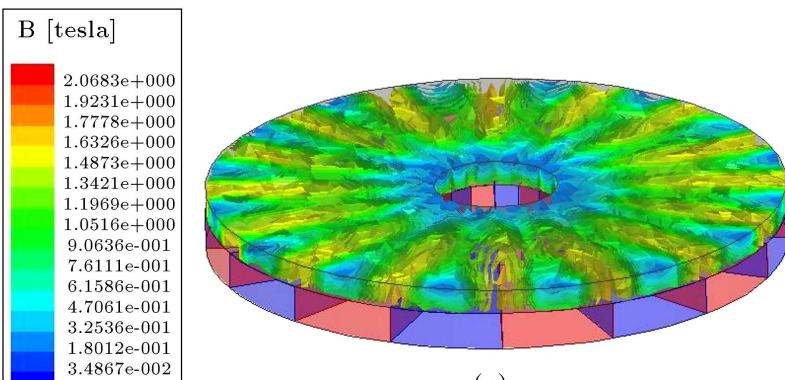

(a)

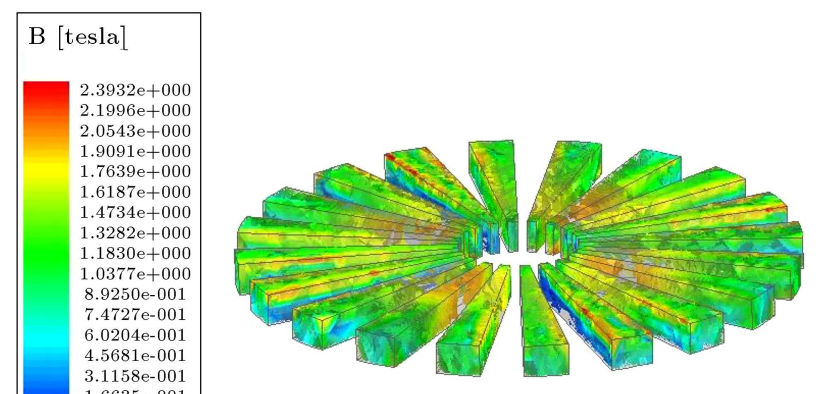

(b)
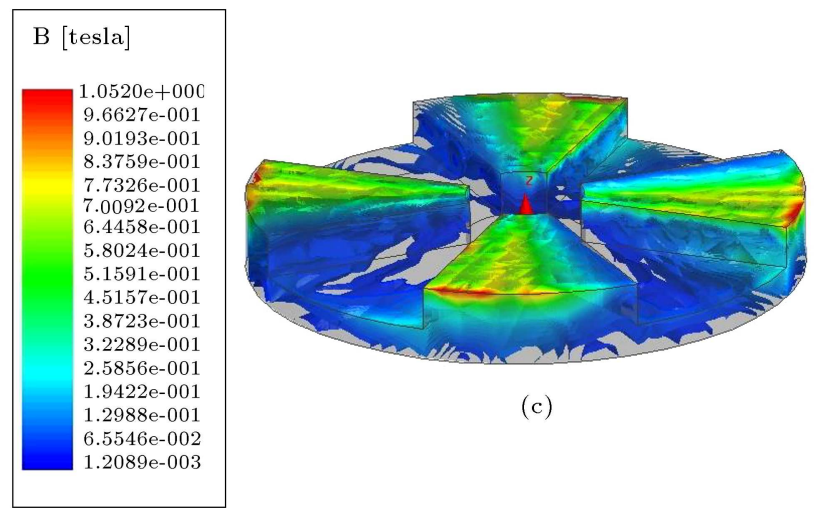

(c)

Figure 6. Flux density magnitude distribution in different rotors of optimal RAMG: (a) Stationary PM rotor, (b) low-speed modulator rotor, and (c) high-speed reluctance rotor.

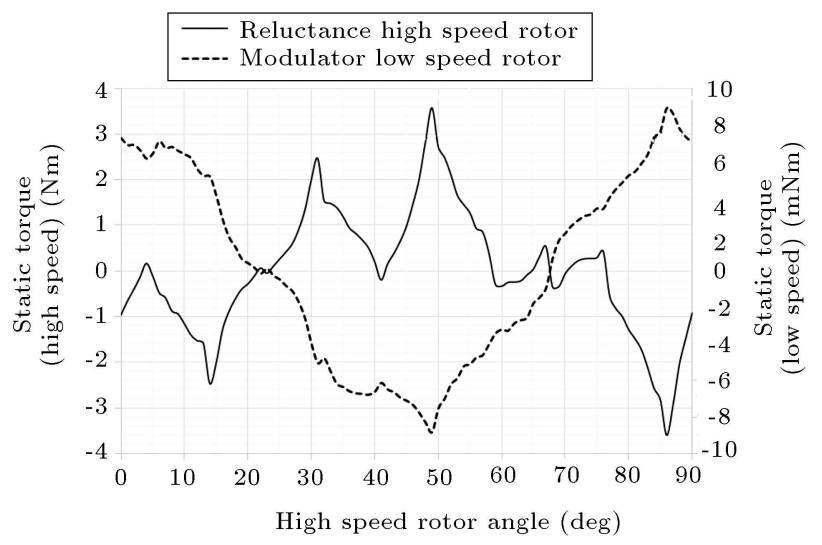

Figure 7. Static torque of high- and low-speed rotors in optimal RAMG. 
Table 2. Output performances of optimal RAMG and initial RAMG.

\begin{tabular}{lcc}
\hline \multicolumn{1}{c}{ Output parameter } & $\begin{array}{c}\text { Initial } \\
\text { RAMG }\end{array}$ & $\begin{array}{c}\text { Optimal } \\
\text { RAMG }\end{array}$ \\
\hline High-speed static torque & $0.74 \mathrm{Nm}$ & $1.5 \mathrm{Nm}$ \\
Low-speed static torque & $3.73 \mathrm{Nm}$ & $7.5 \mathrm{Nm}$ \\
Dynamic cogging torque (high speed) & $3.08 \mathrm{Nm}$ & $4.3 \mathrm{Nm}$ \\
Dynamic cogging torque (low speed) & $1.03 \mathrm{Nm}$ & $1.7 \mathrm{Nm}$ \\
Torque density & $9.6 \mathrm{kNm} / \mathrm{m}^{3}$ & $11.07 \mathrm{kNm} / \mathrm{m}^{3}$ \\
\hline
\end{tabular}

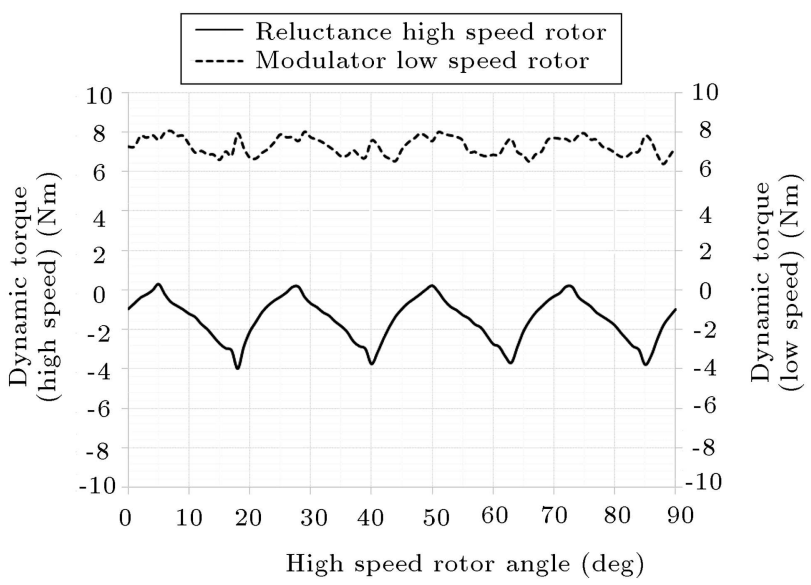

Figure 8. Dynamic torque of high- and low-speed rotor in optimal RAMG.

of different rotor dimensions on the torque density. It was concluded that the optimal dimensions of RAMG led to torque density of about $11.07 \mathrm{kNm} / \mathrm{m}^{3}$.

\section{References}

1. Armstrong, C.G. "Power transmitting device", USA Patent 687,292 (1901).

2. Faus, H.T. "Magnet gearing", USA Patent 2,243,555, (1941).

3. Kikuchi, S. and Tsurumoto, K. "Design and characteristics of a new magnetic work gear using permanent magnet", IEEE Trans. Mag., 29(6), pp. 2923-2925 (1993).

4. Tsurumoto, K. and Kikuchi, S. "A new magnetic gear using permanent magnet", IEEE Transactions on Magnetics, 23(5), pp. 3622-3624 (1987).

5. Atallah, K. and Howe, D. "A novel high-performance magnetic gear", IEEE Trans. on Magn., 37, pp. 28442846 (2001).

6. Mezani, S., Atallah, K., and Howe, D. "A highperformance axial-field magnetic gear", AIP Journal of Applied Physic, 99, pp. 08R303-3 (2006).

7. Ge, Y.-J., Nie, C.-Y., and Xin, Q. "A three dimensional analytical calculation of the air-gap magnetic field and torque of coaxial magnetic gears", Progress in Electromagnetics Research, 131, pp. 391-407 (2012).

8. Jian, L., Deng, Z., Shi, Y., et al. "The mechanism how coaxial magnetic gear transmits magnetic torques between its two rotors: Detailed analysis of torque distribution on modulating ring", IEEE/ASME Transactions on Mechatronics, 24(2), pp. 763-773 (2019).

9. Jian, L. and Chau, K.T. "A coaxial magnetic gear with halbach permanent-magnet arrays", IEEE Trans. on Energy Conv., 25, pp. 319-328 (2010).

10. Jian, L., Chau, K.T., Li, W., et al. "A novel coaxial magnetic gear using bulk HTS for industrial applications", IEEE Trans. on Applied Superconductivity, 20, pp. 981-984 (2010).

11. Jing, L., Liu, L., Xiong, M., et al. "Parameters analysis and optimization design for a concentric magnetic gear based on sinusoidal magnetizations", IEEE Trans. on Applied Supercon., 24(5), pp. 1-5 (2014).

12. Kim, S.J., Kim, C.H., Jung, S.Y., et al. "Optimal design of novel pole piece for power density improvement of magnetic gear using polynomial regression analysis", IEEE Trans. on Energy Conv., 30(3), pp. 1171-1179 (2015).

13. Afsari, S.A., Heydari, H., and Dianati, B. "Cogging torque mitigation in axial flux magnetic gear system based on skew effects using an improved Quasi 3-D analytical method", IEEE Trans. on Magn., 51, pp. 1-11 (2015).

14. Jungmayr, G., Loeffler, J., Winter, B., et al. "Magnetic gear: Radial force cogging torque skewing and optimization", IEEE Transactions on Industry Applications, 52(5), pp. 3822-3830 (2016).

15. Gardner, M.C., Jack, B.E., Johnson, M., et al. "Comparison of surface mounted permanent magnet coaxial radial flux magnetic gears independently optimized for volume, cost, and mass", IEEE Transactions on Industry Applications, 54(3), pp. 2237-2245 (2018).

16. Johnson, M., Gardner, M.C., and Toliyat, H.A. "Design comparison of $\mathrm{NdFeB}$ and ferrite radial flux surface permanent magnet coaxial magnetic gears", IEEE Transactions on Industry Applications, 54(2), pp. 1254-1263 (2018).

17. Wang, Y., Filippini, M., Bianchi, N., et al. "A review on magnetic gears: Topologies, computational models, and design aspects", IEEE Transactions on Industry Applications, 55(5), pp. 4557-4566 (2019).

18. Rahimi, M.A., Durali, M., and Asghari, M. "A design approach for coaxial magnetic gear and determination of torque capability", Journal of Scientia Iranica B, 25(2), pp. 772-789 (2018). 
19. Jing, L., Zhang, T., Gao, Y., et al. "A novel HTS modulated coaxial magnetic gear with eccentric structure and halbach arrays", IEEE Transactions on Applied Superconductivity, 29(5), pp. 1-5 (2019).

20. Afsari Kashani, S.A. "Rotor pole design of radial flux magnetic gear for reduction of flux density harmonics and cogging torque", IEEE Transactions on Applied Superconductivity, $\mathbf{2 9}(8)$, pp. 1-8 (2019).

21. Zhan, Y., Ma, L., Wang, K., et al. "Torque analysis of concentric magnetic gear with Interconnected flux modulators", IEEE Transactions on Magnetics, 55(6), pp. 1-4 (2019).

22. Bahrami Kouhshahi, M., Acharya, V.M., Calvin, M., et al. "Designing and experimentally testing a fluxfocusing axial flux magnetic gear for an ocean generator application", IET Electric Power Applications, 13(8), pp. 1212-1218 (2019).

23. Li, K. and Bird, J.Z. "A review of the volumetric torque density of rotary magnetic gear designs", XIII International Conference on Electrical Machines (ICEM), Alexandroupoli, pp. 2016-2022 (2018).

24. Dianati, B., Heydari, H., and Afsari, S.A. "Analytical computation of air-gap magnetic field in a viable superconductive magnetic gear", IEEE Trans. on Applied Superconductivity, 26, pp. 1-12 (2016).

25. Liu, C., Zhu, H., Dong, R., et al. "Sensitivity analysis and optimal design of a linear magnetic gear for directdrive wave energy conversion", IEEE Access, 7, pp. 73983-73992 (2019).

26. Bomela, W., Bird, J.Z., and Acharya, V.M. "The performance of a transverse flux magnetic gear", IEEE Transactions on Magnetics, 50(1), pp. 1-4 (2014).

27. Afsari, S.A., Heydari, H., and Bashar, E. "Viable arcuate double-sided magnetic gear for competitive torque density transmission capability", Journal of Scientia Iranica D, 23(3), pp. 1251-1260 (2016).

28. Lubin, T., Mezani, S., and Rezzoug, A. "Development of a 2-D analytical model for the electromagnetic computation of axial-field magnetic gears", IEEE Trans. on Magn., 49, pp. 5507-5521 (2013).

29. Khatab, M.F.H., Zhu, Z.Q., Li, H.Y., et al. "Comparative study of novel axial flux magnetically geared and conventional axial flux permanent magnet machines", CES Transactions on Electrical Machines and Systems, 2(4), pp. 392-398 (2018).

30. Yin, X., Pfister, P., and Fang, Y. "A novel magnetic gear: Toward a higher torque density", IEEE Transactions on Magnetics, 51(11), pp. 1-4 (2015).

31. Gardner, M.C., Johnson, M., and Toliyat, H.A. "Comparison of surface permanent magnet axial and radial flux coaxial magnetic gears", IEEE Transactions on Energy Conversion, 33(4), pp. 2250-2259 (2018).

32. Fu, W.N. and Li, L. "Optimal design of magnetic gears with a general pattern of permanent magnet arrangement", IEEE Trans. on Applied Supercon., 26(7), pp. 1-5 (2016).

33. Aiso, K., Akatsu, K., and Aoyama, Y. "A novel reluctance magnetic gear for high-speed motor", IEEE Transactions on Industry Applications, 55(3), pp. 2690-2699 (2019).

34. Yin, X., Fang, Y., and Pfister, P. "A novel singlePM-array magnetic gear with HTS bulks", IEEE Transactions on Applied Superconductivity, 27(4), pp. $1-5$ (2017).

35. Li, X., Cheng, M., and Wang, Y. "Analysis, design and experimental verification of a coaxial magnetic gear using stationary permanent-magnet ring", IET Electric Power Applications, 12(2), pp. 231-238 (2018).

\section{Biography}

Seyed Ahmadreza Afsari received BS degree in Electrical Engineering from K.N. Toosi University of Technology, Tehran, Iran in 2007 and the MSc degree from the University of Kashan, Kashan, Iran in 2010, both in Electrical Power Engineering and the $\mathrm{PhD}$ degree from the Iran University of Science and Technology, Tehran, Iran in 2016. Following graduation, he joined University of Kashan, Kashan, Iran as an Academic Member (Assistant Professor) of the Electrical Power Group. His research interests are magnetic gears, analytical methods, finite-element-methodbased simulation techniques, optimization methods, and applied superconductors in power systems. 